\title{
Ensino de Sistemas Lineares Através do Software GeoGebra Escola Pública x Escola Particular*
}

\author{
Cátia Quilles Queiroz Alex Moreira ${ }^{\dagger}$ \\ Instituto de Ciências Exatas, ICEx, UNIFAL - MG, \\ 37130-000, Alfenas, MG \\ E-mail: alexmoreira11@ hotmail.com, catia@unifal-mg.edu.br.
}

\section{RESUMO}

A Matemática é o ponto mais fraco dos alunos brasileiros, como mostra o último relatório de 2012 do Programa Internacional de Avaliação de Alunos (PISA, na sigla em inglês), no qual apesar da melhora, o Brasil ficou em $58^{\circ}$ entre os 65 países participantes. [?] Em 2007, o Instituto Paulo Montenegro, ligado ao Ibope, entrevistou pessoas de todas as faixas etárias, buscando mapear o analfabetismo funcional matemático, um paralelo com o que é feito na área de humanas, identificando aqueles que sabem ler, mas não entendem o que estão lendo. Pouco menos da metade da população com idade entre 15 e 64 anos, com ensino médio e superior completos, pode ser considerada plenamente alfabetizada em Matemática.

Os Parâmetros Curriculares Nacionais [?] indicam, como objetivos do ensino fundamental, que os alunos sejam capazes de: questionar a realidade formulando-se problemas e tratando de resolvê-los, utilizando para isso o pensamento lógico, a criatividade, a intuição, a capacidade de análise crítica, selecionando procedimentos e verificando sua adequação, além de saber utilizar diferentes fontes de informação e recursos tecnológicos para adquirir e construir conhecimentos.

Este trabalho surgiu da aplicação de atividades em uma escola particular de ensino, durante o cumprimento do estágio curricular, e em uma escola pública de ensino, durante os trabalhos de iniciação à docência (I.D.), e se refere a utilização do software GeoGebra em ambas instituições, que estão situadas na cidade de Alfenas-M.G. A atividade foi elaborada após observar-se que os alunos do ensino particular obtiveram notas insuficientes em um simulado da rede de ensino particular sobre o tema sistema lineares.

O objetivo deste trabalho é apresentar os resultados de uma situação didática aplicada junto aos estudantes do ensino fundamental na escola particular e ao final contrapor a experiência do estágio com as vivências encontradas através do Programa Institucional de Bolsa de Iniciação à Docência (PIBID), na escola pública.

$\mathrm{Na}$ rede particular as atividades foram implementadas com 10 alunos do $8^{\circ}$ ano, durante 2 encontros com 2 períodos de 1 hora, no horário extra-classe. A atividade foi aplicada no laboratório de informática.

Inicialmente, o trabalho foi proposto abordando a história dos sistemas lineares e, em seguida foram aplicadas questões sobre o tema sistemas lineares 2 × 2, utilizando a lousa para que eles montassem o sistema linear, já que, durante toda aula, os alunos mostraram muita dificuldade.

O software de geometria dinâmica GeoGebra, que ainda não era conhecido pelos estudantes, foi apresentado, mostrando os comandos e recursos básicos a serem utilizados. Depois disso foi dado um tempo para que eles explorassem o software. Após essa rápida exploração pediu-se aos alunos que escrevessem na janela de entrada do GeoGebra a equação $x+y=8$. Com isso, eles observaram que tipo de construção apareceu no GeoGebra, e encontraram uma reta, representada na Figura 1. Em seguida, foi pedido aos alunos que escrevessem na janela a equação $-x+2 y=2$, e depois clicassem no ícone "exibir malhas", com a intenção de verificar os pontos por onde as duas retas passam. Assim, usando o

\footnotetext{
${ }^{*} \mathrm{O}$ presente trabalho foi realizado com apoio financeiro da Fundação de Amparo à Pesquisa do Estado de Minas Gerais (FAPEMIG) e do Programa Institucional de Bolsa de Iniciação à Docência (PIBID), da Coordenação de Aperfeiçoamento de Pessoal de Nível Superior (CAPES), Brasil.

†bolsista de Iniciação à Docência PIBID/CAPES
} 
comando "inserir um novo ponto", solicitou-se que os números da tabela fossem encontrados e marcados sobre as retas, e foi obtida a Figura 2.

No GeoGebra, as equações não se juntam, são colocadas separadamente, e assim se obtém o traçado de duas retas num mesmo plano, conforme a Figura 3. Como podemos observar, as retas se interceptam em um ponto. Utilizando o recurso "intersecção de dois objetos", os alunos marcaram esse ponto e determinaram os valores referentes ao " $x$ " e ao " $y$ ".

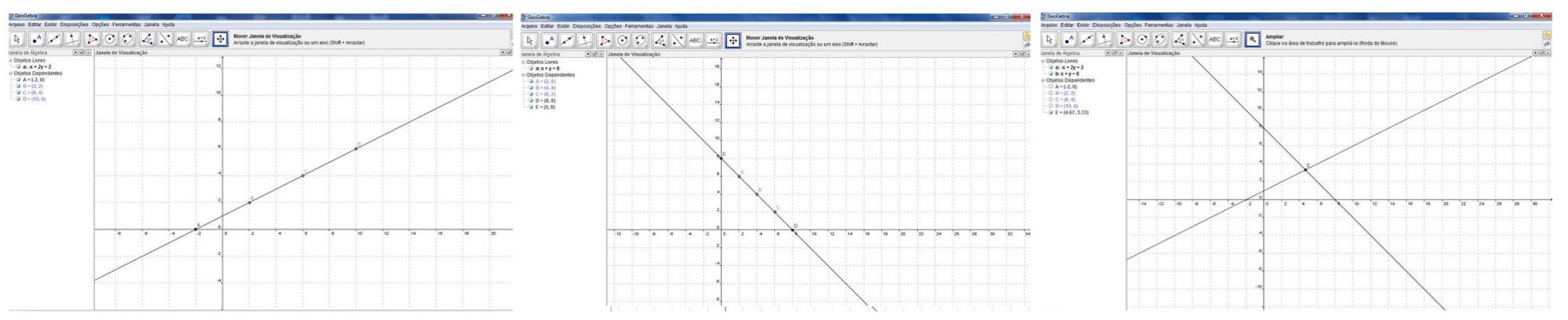

Figura 1, 2, 3: Equações no GeoGebra.

Os estudantes consideraram a atividade bastante motivadora, principalmente por vincular situações de descoberta de conceitos e procedimentos matemáticos ao uso de ferramenta tecnológica, percebendo regularidades nas situações estudadas.

Durante os dois encontros os alunos se mantiveram em constante atenção, foram sanadas todas as dúvidas, e estes se mostraram encantados com o software GeoGebra. Mediante a observação feita, foi detectado que a grande dificuldade dos alunos era realmente na interpretação do problema, ou seja, trabalhar com questões contextualizadas e ter visualizações geométricas em relação ao assunto abordado.

Já na rede pública, foi realizada uma pesquisa em duas escolas sobre o uso do laboratório de informática, onde observou-se uma grande falta de incentivo da escola e apropriação da cultura digital por parte dos professores [?].

Na comparação entre a escola particular e a escola pública, pode-se observar que ambas passam pela mesma dificuldade no que diz respeito a não utilização de recursos computacionais.

Os resultados alcançados com a utilização do software GeoGebra foram satisfatórios, visto que os alunos obtiveram melhores notas na prova de recuperação relacionada ao tema trabalhado extra classe, posteriormente a aplicação. A utilização do software, como um objeto digital de aprendizagem, possibilitou novas perspectivas para a aquisição do conhecimento acerca de sistemas lineares. De acordo com [?], o suporte dos ambientes informatizados favorece a exploração matemática, a elaboração de conjecturas e a gradativa construção de uma teoria matemática.

Observou-se ainda que a participação dos alunos em atividades com uso de tecnologias e de materiais manipulativos tanto na escola pública como no ensino particular, na qual eles experimentam, interagem e vivenciam as situações propostas, se dá de forma mais criativa e dinâmica, auxiliando ainda na compreensão da resolução teórica.

Palavras-chave: ensino fundamental, escola pública x particular, recurso tecnológico, sistemas lineares.

\section{Referências}

[1] Brasil, "Relatório Nacional Pisa 2012: Resultados brasileiros", Fundação Santillana, São Paulo, 2012.

[2] Brasil, "Parâmetros Curriculares Nacionais: Introdução", Brasília, v.1, 1997.

[3] E.K.Odorico; D.M. Nunes; A. Moreira; H.M.P. Oliveira; A. Cardoso, "Analise do não uso do laboratório de informática nas escolas públicas e estudo de caso", Simpósio Brasileiro de informática na educação, XXII, Anais... Rio de Janeiro: Sociedade Brasileira de Computação, p.1-9, 2012.

[4] M.A. Gravina, "Os ambientes de geometria dinâmica e o pensamento hipotéticodedutivo", Tese de Doutorado em Informática na Educação, UFRGS, 2002. Disponível em: http://.hdl.handle.net/10183/2545. Acesso em 20 set.2011. 